\title{
Quality of life of the elderly: a comparison between community-dwelling elderly and in social welfare institutions Stefanus Mendes Kiik ${ }^{1}$, Muhammad Saleh Nuwa
}

${ }^{1}$ STIKES Maranatha Kupang, Nusa Tenggara Timur, Indonesia

\section{ARTICLE INFORMATION}

Received: March 10, 2020

Revised: March 23, 2020

Available online: April 30, 2020

\section{KEYWORDS}

Human; Aged; Quality of life; Social welfare

\section{CORRESPONDENCE}

Phone: +6285288003439

E-mail: stefanusmendeskiik@ymail.com

\section{A B S T R A C T}

Background: Quality of life (QoL) among the elderly is a neglected issue, especially in developing countries, including Indonesia. The QoL of the elderly is dependent on four domains. Living arrangements play an important role in determining QoL.

Objective: The present study aimed to compare the differences in QoL among community-dwelling elderly and in social welfare institutions.

Methods: This was a cross-sectional study. Participants were sampled from two settings: social welfare institutions and the community. The study subjects in each area were selected using a simple random technique. The total sample were 163 respondents. QoL was assessed through the WHOQOL-Bref. Data analysis was performed by the Mann-Whitney U Test.

Results: There were significant differences depending on the residence of the elderly: the average QoL in a community is higher (84.16) than in social welfare institutions (63.95), and p-value $<0.001$.

Conclusions: The results of our study indicate that community-dwelling elderly have higher QoL compared to residents of social welfare institutions.

\section{INTRODUCTION}

At present, the population of older adults has dramatically increased. The World Health Organization (WHO) has estimated that the proportion of the world's older adult population will double from $12 \%$ to $22 \%$ between 2015 and $2050^{1,2}$. In Indonesia, the elderly constituted about $9.34 \%$ (24.75 million) out of a total population of 265 million people in 2018 , and they will make up over $15.77 \%$ of the population by $2035^{3}$.

This aging of the population, along with the epidemiological transition of diseases with an increase in the burden of chronic morbidity conditions, will affect the quality of life of elderly individuals over the long run ${ }^{4}$. Over the last few decades, concern about the QoL in older adults has increased. Studies about the QoL among older adults are essential because they evaluate the efficacy of health interventions, welfare programs, health care, and well-being of older adults ${ }^{5}$. QoL is an necessary aspect of human existence that can be defined as individuals' perceptions of their position in life in the context of the culture and value systems in which they live and in concerning to their goals, expectations, standards, and concerns ${ }^{6}$.

The QoL of the elderly is dependent on various factors, such as physical health, psychological health, living arrangement, level of independence, personal and social relationships, working capacity, access to health and social care, home environment, transportation facilities, and the ability to acquire new skills ${ }^{7}$. The normal aging process and age-related changes can influence the elderly, which in general require a reconsideration of needs, opportunities, and available places of residence ${ }^{8}$.

The environment is a broad concept that includes all aspects of the setting in which care is provided; for dependent older adults, the environment also includes their caregivers. Some elements of the conceptualization may seem contradictory because the situation can be a source of both negative functional consequences and wellness outcomes. For example, the environment is a risk factor when it interferes with functioning, but it also can facilitate wellness outcomes when it is used to improve functioning ${ }^{9}$. 
Community-dwelling elderly is defined as a person $\geq 60$ years old and living independently. The population can suffer from a large variety of health care problems, from just getting older (not diseases specific) to suffering from multiple pathologies. Also, people with accurate medical diagnoses that occur more frequently in an older population, such as stroke, osteoarthritis, or dementia, are part of this group ${ }^{10}$. At the same time, Social Welfare Institution is an institution or a field of activities involving organized activities carried out by the government and private institutions aimed at preventing and addressing social problems as well as at improving the quality of life of individuals, groups, and society ${ }^{11}$. The characteristics of social welfare institution residents are an older adult with vulnerable while community-dwelling elderly is the person who lives with their own home or their family home.

The environment can affect the QoL of the elderly. Different residential settings result in the elderly having to adjust to changes in the role played by the environment. Many changes are experienced by the elderly when moving from a community to a nursing home. The elderly may experience a decrease in autonomy, feel homeless, the changing roles of the family, social economics, and social community has resulted in a decline of the ability to adapt to new environments and interact with their social environment ${ }^{12}$. The lifestyle of the elderly can change dramatically as they move from community to nursing home. Therefore, the nursing home must help the elderly to improve adaptation, independence, stay active to promote the quality of life among the elderly ${ }^{13}$.

The health status and well-being of the elderly are indicated by the existence of the quality of life of this vulnerable group. Therefore, quality of life becomes a concern ${ }^{14}$. Moving to a nursing home is usually synonymous with functional impairment in the elderly ${ }^{14-16}$. The older adults were generally averse to transfer into an institution as they worried about feeling blue and isolated following the transfer ${ }^{17}$.

However, a study has investigated the differences in quality of life among older adults who live in nursing homes and community, ${ }^{18}$ and it was concluded that there are differences ${ }^{19}$. But the study in Indonesia showed that there was no significant difference between the quality of life of the older adults living in the community and a Social Service ${ }^{20}$. Thus, it is necessary to identify the gab in QoL among the elderly who live in the community and social welfare institutions.

The aim of the present study is to compare the differences in QoL among the elderly who live in the community and social welfare institutions.

\section{METHOD}

\section{Study Design}

This was a cross-sectional study.

\section{Setting and Respondent}

Participants were sampled from two different contexts: social welfare institutions (UPT Kesejahteraan Sosial Lanjut Usia Budi Agung Kupang) and a community (Oeltua Village). The sample was selected from each area proportionally to the population of eligible subjects present in each. The study subjects in each region were selected using a simple random technique. The sample consisted of 91 community members and 72 residents of social welfare institutions, for a total of 163 people. Inclusion criteria were all patients older than or equal to 60 years of age; the Katz Index of Activity Daily Living (ADL) scale was 6. Elderly patients who were not willing or in a position to give information for any reason were excluded.

\section{The Variables, Instruments, and Measurements}

In this study, the variables were QoL and socio-demographic data. QoL is individuals' perceptions of their position in life in the context of the culture and value systems in which they live and in concerning to their goals, expectations, standards, and concerns ${ }^{6}$. QoL was assessed through the World Health Organization Quality of Living (WHOQOL)-Bref.

The instrument is a short version of the WHOQOL-100 and contains 26 questions, two addressing general QoL and satisfaction with health and 24 representing each of the 24 facets that comprise the original instrument. It is composed of four domains: physical health, psychological status, social relationships, and environment. The higher the score, the greater the QoL, though there is no cutoff point for its classifications ${ }^{21}$. The Indonesian version of the WHOQOL-BREF is available and has been proven as a valid and reliable questionnaire for use in Indonesia ${ }^{22}$.

Data on socio-demographic characteristics included age, sex, and education. Data were collected on socio-demographic factors of the subjects using a structured questionnaire. ADL was assessed using the Katz ADL scale, which contains six questions on various aspects of daily activities. The score ranged from 0 to 6 , where 6 is the highest score for independence in ADL, and 0 is the lowest score with high dependence on ADL ${ }^{23}$.

\section{Data Analysis}

The Mann-Whitney U Test performed data analysis.

\section{Ethical Consideration}

After obtaining informed consent, the study respondents were interviewed at the community (their homes) and the social welfare institution. All procedures performed were following the ethical standards of the national research 
committee and with the 1964 Helsinki declaration, but this study did not require ethical approval.

\section{RESULTS}

The majority of participants in both groups were female. Community members were slightly younger than the residents in social welfare institutions. More than half of the participants who were community members had only completed elementary school. In comparison, more than half of those in social welfare institutions had completed junior and senior high school (Table 1).

Table 2 shows significant differences between the average QoL among the two settings. Significant differences were depending on the residence of the elderly: the average QoL in the community is higher (84.16) than in social welfare institutions (63.95), and $p<0.001$. The results of further analysis of the four domains of QoL indicate that the QoL of the elderly in the community is higher than in social welfare institutions.

\section{DISCUSSION}

The main findings support the hypothesis that the QoL among community-dwelling elderly was higher than that of the elderly living in a social welfare institution. The analysis carried out on the four domains of life quality showed that the QoL of the community-dwelling elderly was higher than the elderly in social welfare institutions. The physical health domain includes physical pain, life energy, ability to get around, sleep satisfaction, and the ability to perform daily living activities. Older people experience a decrease in physical health due to age-related material changes. The disease also contributes to decreasing physical health. Although they are still able to carry out their daily activities independently, almost all older people in social welfare institutions experience chronic diseases, such as hypertension and diabetes mellitus, which affect their physical health. Chronic diseases such as diabetes mellitus and hypertension can reduce the QoL among elderly ${ }^{24}$. This finding is in line with previous studies suggesting that the presence of a chronic disease decreased quality of life amongst the older adult group ${ }^{14}$.

Judging from the psychological health domain, the elderly in the community have a higher average QoL than the elderly in social welfare institutions. This domain includes the enjoyment of life, feeling meaningful, ability to concentrate, self-satisfaction, acceptance of body appearance, and negative feelings. According to the author, community-dwelling elderly can live independently, close to their spouses, children, and grandchildren, so they are not alone, while elderly persons in the social welfare institution are away from family and rarely meet them. This causes the elderly to have often negative feelings, such as reduced mood, despair, anxiety, and depression, which prevent them from enjoying life. Perception of QoL is directly influenced by depressive symptoms, such as depressed mood, anhedonia, loss of interest, impaired appetite and concentration, sleep disturbances, and social isolation ${ }^{8}$.

Table 1. Demographic profiles of people in social welfare institutions and community-dwelling elderly

\begin{tabular}{|c|c|c|}
\hline Characteristics & Social welfare institutions ( $n=72)$ & Community (n=91) \\
\hline \multicolumn{3}{|l|}{ Age (years): } \\
\hline Mean (SD) & 74.79 (7.99) & $72.27(10.02)$ \\
\hline Min-Max & $60-91$ & $60-100$ \\
\hline \multicolumn{3}{|l|}{ Gender } \\
\hline Female: $\mathrm{n}(\%)$ & $44(61.10)$ & $49(53.80)$ \\
\hline Male: $\mathrm{n}(\%)$ & $28(38.90)$ & $42(46.20)$ \\
\hline \multicolumn{3}{|l|}{ Education } \\
\hline No schooling: $n(\%)$ & $5(6.90)$ & $19(20.90)$ \\
\hline Elementary school: n (\%) & $17(23.60)$ & $68(74.70)$ \\
\hline Junior and senior high school: $n(\%)$ & $50(69.4)$ & $2(2.20)$ \\
\hline University: n (\%) & $0(0)$ & $2(2.20)$ \\
\hline
\end{tabular}

Table 2. QoL scores of social welfare institutions and community-dwelling elderly of each domain

\begin{tabular}{llccc}
\hline Variables & Places & Mean \pm SD & 95\% Cl & p-value \\
\hline WHOQOL Total Score & Social welfare institutions & $63.95 \pm 9.27$ & $61.77-66.13$ & 0.001 \\
& Community & $84.16 \pm 7.29$ & $82.64-85.68$ & \\
Physical health & Social welfare institutions & $60.24 \pm 11.88$ & $57.45-63.04$ & 0.001 \\
& Community & $78.91 \pm 11.05$ & $76.61-81.22$ & \\
Psychological health & Social welfare institutions & $71.96 \pm 17.17$ & $67.93-76.00$ & 0.001 \\
& Community & $91.55 \pm 6.74$ & $90.15-92.96$ & \\
Social relationships & Social welfare institutions & $62.59 \pm 13.66$ & $59.38-65.80$ & 0.001 \\
& Community & $73.21 \pm 11.72$ & $70.77-75.66$ & \\
Environment & Social welfare institutions & $61.02 \pm 12.12$ & $58.18-63.87$ & 0.001 \\
& Community & $92.99 \pm 7.17$ & $91.51-94.48$ & \\
\hline
\end{tabular}


The experience in the institution is attended by a fight for autonomy and against having decisions made for them and actions imposed. It differs from the older adults who live in the community. These findings are consistent with previous studies, being institutionalized might lead to loss of control and lack of autonomy (e.g., when and what to eat, when to sleep, and when to go for a walk) ${ }^{19}$. Many older adults did not like to live in a nursing home because they did not free like in their own homes ${ }^{25}$.

The average domain of elderly social relations in the community is higher than the elderly in the social welfare institution. This domain includes personal relationships, sexual life, and social support. The elderly in the city generally live in the environment where they grew up, so they still has childhood friends and spouses. Most of the elderly in the social welfare institution have no partner or childhood friends. This can make them difficult to get along with and find friends who understand them. Personal relationships, sexual life, and social support can affect QoL. Social networks and social support have been demonstrated to have a positive effect on health ${ }^{26}$. Lack of relationships is a significant strain on the quality of life of elderly ${ }^{27}$. Social support may alleviate the negative impact of loneliness on QoL in elderly ${ }^{28}$.

The fourth domain that affects the QoL of the elderly is the environment. The average environmental area of the community-dwelling elderly is higher than the older person living at home. This domain includes a sense of security, environmental health, adequate money, access to information, recreation opportunities, conditions of residence, and access to health and transportation services. Older people who live with family and people nearby will feel safer. The elderly in the community have their income from pensions, farming, gardening, and livestock. If they need money, the elderly can ask for help from the family. The elderly in a social welfare institution is rarely visited; thus, the opportunity to get money from the family is more limited. This is in accordance with the fact that income is positively correlated with QoL ${ }^{29}$. The higher the income, the greater the QoL.

The relevant factors include better financial situation, greater autonomy in the choice of leisure activities, increased access to goods and services, relationships, and especially, family arrangements ${ }^{30}$. The community-dwelling elderly can also manage the condition of the house as they wish. They have more extensive access to information and more excellent opportunities for recreation than the elderly in the social welfare institution. The elderly can also live more freely in a large environment. They can travel as they wish, while the elderly activities at the social welfare institution are generally located in a small building. Outdoor leisure activity was significantly associated with higher QoL scores ${ }^{5}$.

\section{CONCLUSIONS AND RECOMMENDATION}

The results of our study indicate that community-dwelling elderly have higher QoL compared to residents of social welfare institutions. All domains of elderly QoL in the community are higher than the elderly in social welfare institutions. These findings may suggest a need for community health care to promote community nursing care and suitable programs for older people in social welfare institutions to enhance their physical health, psychological health, social relationships, and the environment. Families are also expected to be able to visit the elderly and not leave them without visiting the social welfare institutions. More studies are needed to explore how quality of life could be improved for social welfare institution residents.

\section{REFERENCES}

1. World Health Organization. Ageing and health. Geneva: World Health Organization. https://www.who.int/en/news-room/fact-sheets/detail/ageing-and-health. Accessed March 20, 2020.

2. Ko H, Park Y, Cho B, et al. Gender differences in health status, quality of life, and community service needs of older adults living alone. Arch Gerontol Geriatr. 2019;83(April):239-245. doi:10.1016/j.archger.2019.05.009

3. Badan Pusat Statistik. Indonesia Population Projection. Jakarta: Badan Pusat Statistik. 2013. https://www.bap-

penas.go.id/files/5413/9148/4109/Proyeksi_Pendu duk_Indonesia_2010-2035.pdf. Accessed July 20, 2018.

4. Karmakar N, Datta A, Nag K, Tripura K. Quality of Life among Geriatric Population: A Cross Sectional Study in a Rural Area of Sepahijala District, Tripura. Indian $J$ Public Health. 2018;62(2):95-99. doi:10.4103/ijph.IJPH

5. Onunkwor OF, Al-dubai SAR, George PP, et al. A cross-sectional study on quality of life among the elderly in non-governmental organizations' elderly homes in Kuala Lumpur. Health Qual Life Outcomes. 2016;14(6):1-10. doi:10.1186/s12955016-0408-8

6. World Health Organization. WHOQOL-BREF: Introduction, Administration, Scoring and Generic Version of the Assessment. Geneva: World Health Organization; 1996. http://www.who.int/mental_health/media/en/76.pdf . Accessed August 5, $201 \overline{8}$.

7. Kwan P, Ali A, Deuri SP. Psychiatric morbidity, quality of life, and perceived social support among elderly population: a community-based study. Open J Psychiatry Allied Sci. 2016;7(1):31-35. doi:10.5958/2394-2061.2016.00007.0

8. Scocco $P$, Nassuato $M$. The role of social relationships among elderly community- dwelling and nursing-home residents: findings from a quality of life study Paolo. Psychogeriatrics. 2017;17(4):231-237. doi:10.1111/psyg.12219

9. Miller CA. Nursing for Wellness in Older Adults. 7th Editio. Philadelphia: Lippincott Williams \& Wilkins; 
2015.

10. Steultjens EMJ, Dekker J, Bouter LM, Jellema S, Bakker EB, Ende CHMVD. Occupational therapy for community dwelling elderly people: a systematic review. Age Ageing. 2004;33(5):453460. doi:10.1093/ageing/afh174

11. Suharto E. Development of Social Welfare in Indonesia: Situation Analysis and General Issues. 2009:1-8. http://www.policy.hu/suharto/Naskah PDF/Development of Social Welfare in Indonesia.pdf. Accessed March 15, 2020.

12. Riedl M, Mantovan F, Them C. Being a Nursing Home Resident: A Challenge to One's Identity. Nurs Res Pract. 2013;2013(4). doi:10.1155/2013/932381

13. Vitorino LM, Paskulin LMG, Vianna LAC. Quality of life of seniors living in the community and in long term care facilities: a comparative study. Rev Latino-Am Enferm. 2013;21(Jan-Feb):3-11. doi:10.1590/S0104-11692013000700002

14. Pramesona BA, Taneepanichskul S. Factors influencing the quality of life among Indonesian elderly. J Heal Res. 2018;32(5):326-333. doi:10.1108/JHR-08-2018-037

15. Bakker C, Vugt ME De, Vliet D Van, et al. Predictors of the Time to Institutionalization in Young- Versus Late-Onset Dementia: Results From the Needs in Young Onset Dementia (NeedYD ) Study. J Am Med Dir Assoc. 2013;14(4):248-253.

doi:10.1016/j.jamda.2012.09.011

16. Brodaty $\mathrm{H}$, Connors $\mathrm{MH}, \mathrm{Xu} \mathrm{J}$, Woodward M, Ames D. Predictors of Institutionalization in Dementia : A Three Year Longitudinal Study. J Alzheimer's Dis. 2014;40:221-226. doi:10.3233/JAD-131850

17. JE H, J R, ME K, JF. R. Management of relocation in cognitively intact older adults. J Gerontol Nurs. 2007;33(11):12-18. doi:10.3928/0098913420071101-05

18. Beerens $\mathrm{H}$, Zwakhalen S, Verbeek $\mathrm{H}$, et al. Change in quality of life of people with dementia recently admitted to long-term care facilities. J Adv Nurs. 2015;71(6):1435-1447. doi:10.1111/jan.12570.

19. Olsen C, Pedersen I, Bergland A, Jøranson N, Calogiuri G, Ihlebæk C. Differences in quality of life in home- dwelling persons and nursing home residents with dementia-a cross-sectional study. BMC Geriatr. 2016;16(137):1-11. doi:10.1186/s12877-016-0312-4

20. Yuliati A, Baroya N, Ririanty M. Perbedaan Kualitas Hidup Lansia yang Tinggal di Komunitas dengan di Pelayanan Sosial Lanjut Usia. e-Jurnal Pustaka Kesehat. 2014;2(1):87-94. https://jurnal.unej.ac.id/index.php/JPK/article/view/ 601/429. Accessed July 6, 2018.

21. World Health Organization. The World Health
Organization Quality of Life (WHOQOL)-BREF. Geneva: World Health Organization; 2004. http://www.who.int/substance_abuse/research_too Is/en/english_whoqol.pdf. Accessed August 15, 2018.

22. Salim OC, Sudharma NI, Kusumaratna RK Hidayat A. Validitas dan reliabilitas World Health Organization Quality of Life-BREF untuk mengukur kualitas hidup lanjut usia. Universa Med. 2016;26(1):27-38.

http://www.univmed.org/ejurnal/index.php/medicin a/article/view/293/246. Accessed July 21, 2018.

23. Mccabe BD. Katz Index of Independence in Activities of Daily Living (ADL). https://consultgeri.org/try-this/generalassessment/issue-2.pdf. Published 2019 Accessed December 5, 2019.

24. Kumar GS, Majumdar A, Pavithra G. Quality of Life (QOL) and Its Associated Factors Using WHOQOL-BREF Among Elderly in Urban Puducherry, India. J Clin Diagnostic Res. 2014;8(1):54-57.

doi:10.7860/JCDR/2014/6996.3917

25. Heggestad AKT, Nortvedt P. 'Like a prison without bars': Dementia and experiences of dignity. Nurs Ethics. doi:10.1177/0969733013484484

26. Raggi A, Corso B, Minicuci N, et al. Determinants of Quality of Life in Ageing Populations: Results from a Cross-Sectional Study in Finland, Poland and Spain. PLoS One. 2016;11(7):1-17. doi:10.1371/journal.pone.0159293

27. Levasseur M, Tribble DS, Desrosiers J. Meaning of quality of life for older adults: Importance of human functioning components. Arch Gerontol Geriatr. 2009;49:91-100 doi:10.1016/j.archger.2008.08.013

28. Liu Y, Qu Z, Meng Z, Wang S. Relationship between loneliness and quality of life in elderly empty nesters from the Wolong Panda Nature Reserve in Sichuan province, China, from the perspective of Rural Population and Social Sustainability. Physica A. 2020;(xxxx):124154. doi:10.1016/j.physa.2020.124154

29. Purba FD, Hunfeld JAM, Iskandarsyah A, et al. Quality of life of the Indonesian general population: Test-retest reliability and population norms of the EQ-5D-5L and WHOQOL-BREF. PLOS One. 2018;13(5):1-20.

doi:10.1371/journal.pone.0197098

30. Alexandre $\mathrm{T}$ da S, Cordeiro RC, Ramos LR Factors associated to quality of life in active elderly Fatores associados à qualidade de vida em idosos ativos. Rev Saúde Pública. 2009;43(4):613-621. doi:10.1590/s0034-89102009005000030 